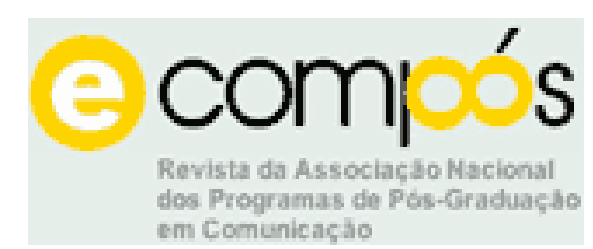

Este artigo foi publicado na edição 1, em dezembro de 2004, da revista eletrônica e-compós: http://www.compos.org.br/e-compos

\title{
CORPO MASCULINO: PUBLICIDADE E IMAGINÁRIO
}

\author{
Tänia Marcia Cezar Hoff ${ }^{1}$ \\ ESPM
}

\begin{abstract}
RESUMO
A crescente oferta de produtos para o público masculino revela o interesse do marketing por novos segmentos. Pretende-se, neste artigo, identificar aspectos do imaginário de corpo masculino na publicidade brasileira atual -- mídia impressa - e analisar sua apropriacao pelo mercado.

A partir de alguns pressupostos teóricos de Iuri Lotman, abordamos as questões relativas à cultura e ao corpo, considerando que o corpo humano é um texto de cultura. Na Antropologia, buscamos respaldo na teoria de Gilbert Durand para compreender como o imaginário cultural e formado e, na filosofia, baseamo-nos nas idéias de Michel Foucault acerca do corpo na sociedade disciplinar para analisar a sua utilização na publicidade.
\end{abstract}

Palavras-chave: Publicidade brasileira, imaginário, corpo masculino, mercado.

\section{RÉSUMÉ : Le corps masculin : publicité et imaginaire}

L'offre croissante de produits au public masculin révèle l'intérêt que le marketing porte à de nouveaux segments. Nous nous proposons d'identifier, dans cet article, des aspects de l'imaginaire du corps masculin dans la publicité brésilienne actuelle - en particulier dans la presse écrite - et d'analyser la manièrè dont le marché s'en approprie.

À partir de quelques présupposés théoriques de Iuri Lotman, nous abordons les questions relatives à la culture et au corps, en considérant le corps humain comme un texte de culture. En anthropologie, nous nous appuyons sur la théorie de Gilbert Durand pour comprendre comment l'imaginaire culturel se constitue et en philosophie, nous nous basons sur les idées de Michel Foucault concernant le corps dans la société disciplinaire pour analyser l'utilisation du corps dans la publicité.

Mots-clés: Publicité brésilienne, imaginaire, corps masculin, marché.

\section{ABSTRACT : Male body: advertising and imaginary realm}

The increasing offer of products to the male public reveals the interest of marketing in new segments. we intend, in our article, to identify aspects of the imaging of the male body in recent Brazilian advertising, particular in printed media - and to analyse its appropriation by market. 
On the basis of some of Iuri Lotman's theoretical assumptions, we approach the issues that are relative to culture and body, considering the human body a culture text. In anthropology, we rely on Gilbert Durand's theory in order to understand how the cultural imaginary realm is formed and in philosophy, we base our reflections on Michel Foucault's ideas concerning the body in disciplinary society in order to analyse the way the body is used in advertising.

Keywords: Brazilian advertising, imaginary realm, male body, market

\section{RESUMEN: Cuerpo masculino: publicidad e imaginario}

La creciente oferta de productos para el público masculino da a conocer el interés del marketing por nuevos segmentos. En este artículo, se pretende identificar los aspectos del imaginario del cuerpo masculino en la publicidad brasileña actual divulgación impresa - y analizar su apropiación por el mercado.

A partir de algunas presuposiciones teóricas de Iuri Lotman, abordamos a las cuestiones relativas a la cultura y al cuerpo, al considerar que el cuerpo humano es un texto de cultura. En la Antropología, buscamos el respaldo en la teoría de Gilbert Durand para entender como el imaginario cultural es formado y, en la filosofía, nos basamos en las ideas de Michael Foucault acerca del cuerpo en la sociedad disciplinar para analizar su utilización en la publicidad.

Palabras-clave: Publicidad brasileña, imaginario, cuerpo masculino, mercado.

A publicidade pode ser considerada uma espécie de crônica social, uma vez que estabelece um diálogo com os acontecimentos do presente e com as tendências de comportamento, expectativas, desejos e percepções do público e que traduz a concepção econômico-mercadológica da sociedade em que está inserida.

Enquanto produção cultural, o discurso publicitário constrói-se a partir das representações do consumo e registra o(s) imaginário(s) dos grupos sociais aos quais se destina. Uma campanha publicitária -- ou mesmo uma peça publicitária contém traços do imaginário de um grupo social acerca de um determinado aspecto da vida.

Há, por exemplo, um modelo de corpo feminino difundido pela publicidade, mas o que dizer do masculino? Existe um modelo e um imaginário de corpo masculino? Como a sociedade de consumo representa e significa o corpo masculino?

\section{Imaginário e publicidade}


Gilbert Duranđ, imaginário (1998), apresenta características do imaginário social ou cultural. Diferente da taxinomia clássica que se constrói a partir do princípio de uma identidade "exclusiva", ou seja, única e excludente de qualquer "terceiro" -- elemento --, o imaginário é alógico: fundamenta-se no pluralismo, na idéia de que existem fenômenos que se situam num espaço e tempo completamente diversos, passíveis até de reversão. Trata-se da lógica do mito, uma lógica diversa daquela da ciência.

O imaginário pressupõe um conjunto relacional de vários elementos que podem até ser contrários ou contraditórios. Reside nele uma "abertura necessária" e uma "flexibilidade" que o constitui como um sistema. Sua característica sistêmica permite-lhe comportar a ambigüidade, superando a lógica bivalente, que é excludente -- A exclui não-A --, ao pressupor sempre o terceiro.

Para uma tópica sociocultural do imaginário, Durand estabelece algumas correlações com as três dimensões da mente proposta por Freud -- superego, ego e id. No "trajeto antropológico", há duas instâncias: uma superficial, "educada" e outra, profunda, denominada "inconsciente específico". A instância superficial corresponde ao supergo e ao ego na teoria freudiana e o "inconsciente específico", ao id -- o que Jung denomina "inconsciente coletivo".

O imaginário, para Durand, é um conjunto formado por imagens e é constituído pelo "inconsciente específico" -- que corresponde ao id e também ao ego -- e pela parte "educada", instância superficial, que corresponde ao superego da sociedade. A instância profunda, denominada "inconsciente específico", "guarda" as imagens simbólicas e os esquemas arquetípicos que produzem as imagens arquetípicas. Também no "inconsciente específico" são construídas as estratificações sociais que modelam os papéis conforme classes, faixa etária, sexo, grau de parentesco etc (1998:93-94).

Já a instância superficial do imaginário corresponde à sociedade, ou seja, aquilo que se manifesta efetivamente na vida em sociedade. A instância superficial é o lugar das regulamentações sociais: a organização de códigos de conduta -- leis, por exemplo -- e de comunicação -- as linguagens. É o espaço da racionalização, onde a razão atua formatando a vida em sociedade. 
No nível do "inconsciente específico", há uma profusão de imagens que vão se regularizando a medida em que se aproximam da superfície. As imagens dos papéis positivamente valorizados tendem a se institucionalizarem e a se sedimentarem em códigos próprios, perdendo a flexibilidade e a riqueza de significação. Assim, quanto mais sedimentada uma imagem na instância superficial do imaginário, mais empobrecida a encontraremos.

As imagens trazidas da instância superficial e expressas em produções culturais tendem a ser mais reprodutoras das significações atuais que "revolucionárias". Já as imagens trazidas do "inconsciente específico" tendem a alimentar as produções culturais com inovações, pois são conteúdos latentes da cultura que podem ser potencializados. As imagens institucionalizadas e, portanto, sedimentadas da instância superficial podem ser consideradas um entulho do imaginário, já que não possibilitam diferentes compreensões da realidade: reduzem e ocultam o imaginário em potencial, carregado de novidade.

A publicidade é caudatária, faz uma espécie de "narrativa" do passado e instaura-se no presente para alimentá-lo e divulgá-lo. Assim considerada, publicidade e mito aproximam-se em alguns aspectos. A mensagem publicitária, dada sua organização analógica, opera por saltos, de imagem a imagem, ou de idéia a idéia, assemelha-se à organização alógica do mito. Note-se também que ambos divulgam princípios gerais, isto é, informações necessárias para a manutenção dos significados culturais e alimentam-se dos conteúdos do imaginário e de sua constituição sistêmica, isto é, não excludente, já que podem acolher as idéias e imagens mais dispares entre si.

Os mitólogos são unânimes em apontar que a repetição -- a sincronicidade -das ligações simbólicas que compõem um mito garantem a compreensão da verdade: é a repetição que garante a assimilação do significado do mito. Comparativamente, a repetição consiste num dos aspectos que auxiliam no processo de decodificação de uma peça ou campanha publicitária.

Se, por um lado, a repetição facilita a memorização e a compreensão de uma mensagem, tornando seu conteúdo ou parte dele objeto de referência do público na vida cotidiana; por outro, pode provocar o desgaste da imagem de um 
produto/serviço/marca. A banalização de uma imagem resulta na perda de valor, ou de significado.

Repetição é, portanto, procedimento basilar de manutenção de cultura. Neste sentido, a instância superficial do imaginário comporta um certo grau de banalização, pois a sedimentação e a institucionalização são conseqüência da repetição de determinados conteúdos. Assim, a publicidade, ao se repetir, tanto pode reforçar como desgastar significados culturais já conhecidos.

Um outro aspecto a se considerar quanto ao mito refere-se ao conteúdo da informação que se repete: o mito apresenta explicações acerca da vida de uma sociedade -- sua função é disciplinadora, ou seja, é um mecanismo de manutenção do poder. A publicidade, como uma manifestação midiática que divulga e afeta a formação de repertório de determinados grupos, também pode ser entendida como um mecanismo de manutenção do poder já que reflete e divulga valores dos grupos dominantes, ou seja, aqueles que têm o poder econômico, e tende a influenciar os grupos de menor poder aquisitivo.

Ao buscar aproximação com o público, isto é, utilizar elementos do seu repertório, a mensagem publicitária mantém-se em estreita relação com os acontecimentos e interesses dos grupos aos quais se destina. Em conseqüência, utiliza intensamente de representações sedimentadas, provenientes da instância superficial do imaginário e, por isso, tende a valorizar imagens conhecidas e aceitas. No entanto, também precisa despertar interesse, atrair a atenção do público e criar impacto, em outros termos, precisa ser original. Para esta situação, sai da condição de simples reprodutora de valores e timidamente inicia a divulgação de conteúdos não sedimentados -é o que se observa em campanhas de produtos e serviços posicionados como inovadores e que possibilitam a divulgação de tendências, valores e comportamentos emergentes.

As imagens de corpos masculinos em peças ou campanhas publicitárias representam, na sua maioria, o homem em papéis sociais bastante difundidos: provedor, trabalhador, pai e marido. Esses papéis sociais expressam a instância superficial do imaginário, com a rigidez da institucionalização e da regulamentação, pois carregam informações de "domínio público". No entanto, nota-se na publicidade um aumento gradativo, a partir dos anos 1990, de imagens 
de corpo masculino fora dos papéis sociais mencionados acima -- exposição do corpo de forma erótica, preocupação com beleza e moda. São novas representações do corpo masculino e provavelmente expressem conteúdos da instância profunda do imaginário.

Ao associar os conteúdos do imaginário cultural aos da concepção econômico-mercadológica da sociedade atual, o discurso publicitário ramifica-se na cultura e pode tanto revelar e/ou atualizar aspectos ocultos da memória social quanto reforçar imagens sedimentadas e desgastadas.

\section{Corpo e cultura}

Segundo o semioticista Iuri Lotman (Lucid, 1980:213), cultura é "informação não hereditária, adquirida, preservada e transmitida por vários grupos da humanidade". A cultura tem uma dimensão sígnica; é, pois, representação.

Nesta perspectiva, o corpo pode ser entendido como um texto de cultura, pois a identidade cultural dos indivíduos está inscrita no corpo: as representações produzidas para ele informam o que uma sociedade é, como vive e como, no corpo, registra o seu fazer e, também, suas aspirações.

O corpo é mídia: veículo de comunicação. Dadas as muitas linguagens que comporta, expressa em linguagens diferentes os significados de uma cultura e divulga seus aspectos basilares. No corpo, os significados da cultura ganham materialidade: não são apenas o corte de cabelo, a cor da pele, o peso e os adereços que materializam a cultura, também os ossos e a carne são moldados: os pés atrofiados das mulheres orientais, os lábios deformados de determinadas comunidades indígenas, até os músculos super desenvolvidos dos fisiculturistas e as próteses, dentre tantos outros exemplos.

Texto vivo, o corpo pode ser entendido como um artefato arqueológico que guarda informações culturais confiáveis. Na cultura, as histórias do corpo, da política e da economia se inter-relacionam: não é possível re-criar o corpo-texto sem considerar um conjunto de fatores - revelados e ocultados -- que contribuíram para a sua produção. A cultura, em especial a do consumo, se materializa nos produtos desenvolvidos para o corpo: a recente descoberta do público masculino 
pelo mercado promoveu o desenvolvimento de produtos e serviços de beleza e de moda. Novas informações serão registradas no texto-corpo masculino e um processo de re-significação tem início com tal tendência de mercado.

Associa-se ao conceito de cultura o de não-cultura, ou seja, uma organização para além do âmbito da cultura instituída que não é percebida ou aceita pelos parâmetros da cultura instituída, até o momento em que as fronteiras da cultura se expandem em direção à não-cultura e a incorporam.

O movimento de incorporação da não-cultura pela cultura pode ser visualizado na mudança de valores atribuídos à compleição física dos corpos: há menos de um século, um corpo magro, que permitisse visualizar o contorno dos ossos, seria considerado doente, tísico, contrário à noção de saúde e de beleza vigentes na cultura brasileira; hoje, corpos com tal compleição são valorizados e desejados. A cultura alimenta-se constantemente da não-cultura num eterno movimento de aceitação e/ou transformação do excluído -- o corpo magro -excluído -- foi assimilado e transformado em modelo de corpo belo e saudável.

A crescente presença do corpo masculino na mídia exemplifica o processo de incorporação da não-cultura: somente no final do século XX, a ciência e a mídia empreenderam leituras deste corpo-texto e o revelaram na cultura. Apesar de existir enquanto materialidade e guardar informações, permaneceu inalterado na rede de significados que se manifestam na cultura. Quando algo não significa ou se mantém silenciado, não comunica - não existe.

Nesse sentido, o corpo masculino e mesmo a masculinidade permaneceram intocados; uma espécie de tabu: paralisados do tempo, passando ao largo das discussões a respeito do corpo feminino. Talvez as rupturas promovidas pelas discussões a respeito do feminino e da feminilidade tenham despertado o interesse pelo o masculino e pela masculinidade: a publicidade tem revelado as transformações de sentidos atribuídos ao corpo, na medida em que as expressa.

Nas revistas estudadas, predominam os anúncios com presença de corpo como signo dominante. O público se reconhece -- identifica-se -- com o modelo do anúncio que, em algum de seus aspectos, o representa. O igual é real demais para chamar a atenção e comportar algum grau de persuasão. A imagem melhorada do 
corpo do outro produz a identificação a partir da projeção - a imagem desejada --: não se busca um corpo igual, mas um corpo que se gostaria de ter.

O corpo da publicidade não é igual aos do cotidiano, é melhor, mesmo que exista a preocupação de representar pessoas comuns e seus corpos também comuns. O comum na publicidade é idealizado: as imperfeições do comum desaparecem. Trata-se do "aprimoramento" estético que a imagem publicitária promove nas suas representações de corpo.

Nos anúncios veiculados nas revistas estudadas ${ }^{2}$, observa-se maior incidência de corpo feminino. Objetivando uma amostragem comparativa da presença do corpo feminino em relação ao masculino em algumas das revistas -Nova, Claudia, Playboy, G Magazine, Raça, Contigo e Viva! --, publicadas em dezembro de 200o, elaboramos o quadro abaixo, embora seja uma amostragem de caráter unicamente exploratório e sem valor estatístico3.

Quadro 1. ANÚNCIOS VEICULADOS EM DEZEMBRO DE 2000

\begin{tabular}{|c|c|c|c|c|}
\hline REVISTA & $\begin{array}{c}\text { Total } \\
\text { de } \\
\text { Anúncios* }\end{array}$ & $\begin{array}{c}\text { Imagem } \\
\text { Corpo } \\
\text { feminino }\end{array}$ & $\begin{array}{c}\text { Imagem } \\
\text { Corpo } \\
\text { masculino }\end{array}$ & $\begin{array}{c}\text { Imagem } \\
\text { Corpos } \\
\text { F/ M }\end{array}$ \\
\hline Nova & 79 & 47 & 02 & 11 \\
\hline Claudia & 90 & 40 & 04 & 07 \\
\hline Playboy & 63 & 07 & 25 & 07 \\
\hline G Magazine & 56 & 01 & 30 & 02 \\
\hline Raça & 18 & 10 & 01 & 02 \\
\hline Contigo & 72 & 25 & 11 & 02 \\
\hline Viva! & 93 & 40 & 05 & 11 \\
\hline TOTAL & $\mathbf{3 3 9}$ & $\mathbf{1 7 0}$ & $\mathbf{7 8}$ & $\mathbf{4 2}$ \\
\hline
\end{tabular}

* Foram contabilizados todos os anúncios veiculados na revista, independente de ter ou não imagem.

Fonte: Elaborado pela autora.

No Quadro 1, observa-se que a imagem de corpo feminino predomina nos anúncios veiculados nas revistas estudadas. Somente nas revistas Playboy e G 
Magazine, posicionadas para públicos masculino, há maior ocorrência de corpo masculino. A revista Raça destaca-se pelo número reduzido de anúncios: talvez não esteja consolidada como veículo de comunicação publicitária no segmento de mercado em que atua.

\section{O corpo na publicidade}

Por que o corpo feminino é alvo de especulações práticas e teóricas há alguns séculos em detrimento do masculino? Para Michel Foucault (1999), o saber sobre o corpo se desenvolve a partir do século XVII, com a Medicina, expande-se para outros campos como a sexualidade, a psicanálise, a psiquiatria, a ortopedia etc. Ao tratar do controle do corpo, permite-nos entrever que as práticas da medicina estavam voltadas para o corpo feminino. Quatro séculos de significados constroem um imaginário.

O corpo feminino manteve-se, por oposição ao masculino, como centro de interesse: se os homens detêm o poder nas sociedades patriarcais, o olhar masculino fundamentou a perspectiva desde a ciência até as artes. O imaginário de corpo feminino foi construído ao longo dos últimos séculos a partir do olhar masculino que privilegiou a alteridade: que segredos esconde o "outro" corpo, diferente e, por isso mesmo, objeto de especulação.

Do rico imaginário de corpo feminino apenas alguns conteúdos são utilizados na publicidade de forma recorrente: em especial aqueles da instância superficial que alimentam com suas imagens institucionalizadas e pouco espontâneas nossas criações culturais midiáticas. No entanto, como há muitas facetas para se esse corpo, encontram-se imagens de corpo feminino em diversos papéis sociais: mãe, sedutora, mulher fatal, amiga, etc.

Por sua vez, o corpo masculino permanece oculto. Pouco se falou e ainda pouco se fala dele na nossa cultura. As produções midiáticas atestam esse ocultamento. Fala-se do corpo de modo genérico -- a espécie, o homo sapiens --; entretanto, o corpo masculino praticamente inexiste: parece não ter identidade ou não ter se constituído da forma como o feminino se fez -- fortemente marcado pela 
materialidade e pela diversidade de papéis sociais - mesmo que a erotização do corpo feminino seja intensa na publicidade, outras percepções são utilizadas.

O corpo feminino da publicidade significa, predominantemente, formas: medidas (peso, altura), proporções, sensações, prazer. Máxima expressão de materialidade! O imaginário de corpo feminino foi construído pelo olhar masculino (GIDDENS, 1993); portanto, faz sentido identificarmos uma objetivação no aspecto físico: determinadas partes têm uma representação bem conhecida pelos homens e também pelas mulheres, o que revela que o imaginário de corpo feminino tem muitos afluentes que ainda significam na rede de sentidos do tecido social.

O mesmo não se pode dizer a respeito do corpo masculino: como é valorado, que idéias a seu respeito são conhecidas em larga escala pela sociedade? Que imagens representam esse corpo?

O corpo masculino ainda nos é desconhecido e, provavelmente em decorrência deste fato, permanece sem forma. Se considerarmos o olhar feminino na construção do corpo masculino, esbarraremos nas diferenças entre os gêneros que são diferentes. $\mathrm{O}$ olhar masculino e o feminino vêem o mundo de formas distintas: os valores não são os mesmos.

O olhar feminino parece não ver no corpo masculino uma forma -- como o masculino vê no feminino. Os filtros do olhar feminino não são os mesmos: daí não haver uma imagem física estabelecida e reconhecida como o corpo do homem brasileiro, por exemplo.

No olhar feminino, o foco não recai sobre a materialidade do corpo. A mulher tende a representar o corpo do homem por meio de aspectos subjetivos. Frases como: "um homem bonito é um homem carinhoso"; "o homem precisa ser sensível"; o homem não pode ser descuidado" etc., não revelam como é a materialidade deste corpo. Ressalte-se que a revista Íntima ${ }^{4}$ não prosperou no mercado editorial: teve somente alguns números publicados. Os valores do públioalvo -- mulheres - seria um dos motivos que levaram a referida revista a sair de circulação?

G Magazine, Sex Simbol, também revistas de nu masculino, mas posicionadas para o público homossexual tiveram melhor sorte e permanecem em circulação. Nestas revistas, por exemplo, observamos a objetivação genital do 
corpo, traço que parece fundamentar o imaginário masculino acerca do corpo feminino. Os ensaios fotográficos de nu masculino muito se assemelham aos de nu feminino no que se refere aos enquadramentos de determinadas partes do corpo.

As revistas de nu masculino que existem no mercado editorial brasileiro destinam-se ao público homossexual masculino e, nelas, podemos perceber a mesma percepção da materialidade do corpo que parece fundamentar o imaginário do corpo feminino. O enfoque recai em partes do corpo -- observa-se a mesma objetivação genital das imagens do corpo feminino em revistas de nu destinadas ao público masculino.

O corpo masculino representado nas revistas de nu é, pois, uma construção sob a ótica masculina -- são revistas para homens, produzidas e consumidas na visão masculina. Daí a objetivação genital e a transposição das imagens do corpo feminino para o corpo masculino: as poses, o enquadramento dos corpos, a formatação do ensaio de fotos -- como ele se desenvolve desde a apresentação do modelo até o detalhamento de determinadas partes de seu corpo -- revelam que ainda não há um formato de nu específico para o corpo masculino. O que predomina, hoje, é o empréstimo -- a transposição -- do modus operandi de se fazer o nu feminino.

Na publicidade, a presença de imagens de corpos masculinos é significativamente menor que a de femininos e são raras as imagens de corpos masculinos seminus. Nas revistas estudadas, ao longo do segundo semestre de 2000, menos de dez anúncios com imagem de corpo masculino seminu foram encontrados. É um número muito reduzido, se se considerar que o número de anúncios veiculados é superior a mil.

Os anúncios veiculados revelam o corpo masculino a partir dos papéis sociais: homem-pai; homem-amigo; homem-marido; homem-profissional; homem-amante; homem-investidor; homem-cantor; etc.

Quanto ao corpo em sua expressão física, está oculto! Ou melhor, encontrase representado, na imagem publicitária, coberto por roupas de grife -- as mais diferentes marcas e estilos, mesmo que o anúncio não seja de roupas --, mas é inexpressivo. Trata-se de um corpo vestido: a roupa e os acessórios dão-lhe forma e status, apresentam-no e atribuem-lhe sentidos de caráter social, comercial que lhe 
são externos. De fato, nada -- ou muito pouco -- há no corpo masculino da publicidade que o revele na sua materialidade e lhe confira uma identidade para além dos acessórios ao seu redor. Não há uniformização dos atributos físicos do corpo masculino - embora sejam observadas características como ombros largos e músculos desenvolvidos nas poucas imagens de corpos masculinos seminus, não se pode ainda considerá-las traços constitutivos de um imaginário de corpo masculino brasileiro.

Comparativamente, o imaginário de corpo feminino, apesar de bastante institucionalizado, mostra-se mais rico, pois o corpo masculino ainda encontra-se preso às máscaras sociais que o ocultaram. Trata-se de um momento de transição: talvez, a busca por novos e diversificados olhares para questões de gênero, de sexualidade e papéis sociais crie condições para uma percepção mais rica e menos empobrecida da masculinidade e do corpo masculino.

A já referida situação de transição observada no período 2000-2001 apresenta-se intensificada: atualmente, coexistem tanto imagens de corpo masculino identificadas com um discurso "prêt-à-porter" - representação sedimentada e, embora construção social, quase naturalizada -- sobre a masculinidade (LINS: 09) quanto novas perspectivas ou tendências. Ou seja, ao lado de imagens que representam o homem-provedor, pai, trabalhador encontramse imagens de homens eróticos, atletas, "descolados" etc.

\section{O consumo do corpo masculino}

A concepção econômica que se desenvolve a partir do século XVIII é responsável por muitas transformações, dentre as quais a transformação do corpo em corpo-produto (KURZ, 2001). Como a mercadoria não tem gênero, o corpo masculino e o feminino são tratados de forma idêntica.

O marketing constitui um saber sobre a mercadoria e transpõe, para o corpo, as suas normas de controle: erradica a doença ou as imperfeições e estabelece um novo modelo de corpo -- belo, saudável e produtivo - no mercado. Sua profilaxia consiste em banir do corpo tudo o que lhe é natural -- como se os 
aspectos de natureza fossem uma enfermidade --, e transformá-lo em um corpomodelo, ou melhor, em um corpo-mercadoria.

No discurso econômico, o corpo-mercadoria recebe tratamento semelhante ao do produto: deve ser planejado e definido conforme princípios do marketing, ou seja, obedecendo às regras que emanam do mercado. Trata-se de um corpo que informa e representa a concepção mercadológica.

Conforme Camargo \& Hoff (2002), o corpo-mercadoria do marketing construído num percurso gradativo de controle: primeiro, a compreensão da sexualidade do corpo; depois, a associação da saúde à estética; e, finalmente, a construção de padrões de corpo e de beleza, que devem ser divulgados na publicidade.

Os corpos masculinos e femininos presentes na publicidade, embora apresentem aspectos distintos no que se refere aos respectivos imaginários, desempenham a mesma função: são corpos-produto carregados de significações próprias do imaginário da mercadoria. Os corpos, independente de seu gênero, são revestidos pelos valores do consumo. Neste sentido, assemelham-se, pois perdem a identidade de gênero (BREEN, 1998).

Os corpos-produto são estetizados e encontram-se em constante exibição (GIDDENS, 1998), são apresentados como mercadoria e, como tal, obedecem às táticas de venda: passam por uma criteriosa análise de eficiência e de qualidade -encontram-se disciplinados, controlados, catalogados e classificados. As revistas de nu masculino são exemplos da estetização do corpo masculino e da divulgação de padrões de beleza para este corpo.

$\mathrm{O}$ produto nunca fenece ou definha: procura apresentar-se perfeito na sua máxima capacidade de satisfazer o consumidor. Como tudo que circula como mercadoria, os corpos-produto sofrem do mal da saturação, vivem a superexposição e parecem, sempre, disponíveis.

Belo, perfeito, pleno na capacidade e potencialidade de satisfação dos desejos do consumidor, ele circula até a saturação. Observa-se a substituição dos corpos nas revistas de nu feminino e também nas de nu masculino: a cada edição, um novo corpo. Nas peças e campanhas publicitárias, observa-se o mesmo fenômeno: há renovação da imagem - design da embalagem, do logo e do 
modelo/garoto(a) propaganda -- toda vez que a marca ou o produto estiverem desgastados.

Os corpos-produto pertencem à realidade dos shopping center e sofrem os efeitos da proliferação que os faz aparecer e desaparecer na velocidade das coisas efêmeras. Tal proliferação é necessária para manter a novidade: uns são substituídos por outros substancialmente semelhantes, pois todos eles apresentam o mesmo padrão estético.

No corpo-produto, pode-se perceber uma subversão no jogo das aparências: as questões relativas ao masculino e ao feminino desaparecem. As relações comerciais não levam em consideração o gênero e extraem do humano o que pode ser transformado pela cultura do consumo: o desejo, que é falta e que não comporta classificações como masculino ou feminino.

Em suma, os corpos são os mais complexos e eficazes dispositivos de poder a serviço do saber econômico (FOUCAULT, 1987). Há uma única economia para todos. Os corpos masculino e feminino encontram-se disciplinados por táticas e práticas de consumo e representam índices de venda, taxas de crescimento de mercado, porcentagem destinadas a investimentos em diversos setores.

Os corpos-produto são cifras que devem ser estudadas e controladas para o bom desenvolvimento econômico da sociedade. O imaginário dominante é o da mercadoria, o das relações econômicas que suplantam as diferenças de gênero.

\section{Considerações finais}

O imaginário social é uma projeção do real, por isso comporta uma relação entre o real e o irreal. A publicidade tende a ocultar a dimensão real e a explorar a irreal: nas peças veiculadas nas revistas estudadas encontram-se apenas imagens de corpos perfeitos, saudáveis, adequados aos padrões de ideal de beleza do nosso tempo.

A supressão da dimensão real na imagem publicitária é uma evidencia da virtualização de corpo que caracteriza a nossa época. Não queremos o real! O imaginário de corpo suplantado pelo imaginário da mercadoria revela este aspecto 
fundamental dos valores da sociedade contemporânea. Assim, o imaginário social é unívoco para o corpo -- considerado corpo-produto, iguala os corpos, suplantando a noção de gênero e empobrecendo as produções culturais no que se refere à masculinidade e à feminilidade.

Tal aspecto pode ser observado no crescente interesse do mercado pelo público masculino: os melhores índices de crescimento referem-se á indústria da beleza e da moda, o que sugere não haver inovação quando o mercado amplia as fronteiras em direção a novos segmentos. O corpo masculino não é abordado numa perspectiva inovadora: apenas foram transpostos para o corpo dos homens os mesmos tratamentos de beleza já existentes para mulheres. Pode-se estabelecer a analogia entre mulher-objeto e homem- objeto.

O corpo masculino parece ter entrado em evidência como um substituto ou uma possibilidade a mais em relação ao corpo feminino, já tão exposto. Trata-se de mais uma possibilidade mercadológica, pois não há alteração no tratamento e na abordagem do corpo nas mensagens publicitárias. Isto implica concluir que não há avanço/modificação na nossa compreensão de corpo: o valor mercadológico do corpo feminino foi transposto para o corpo masculino; agora, ambos alcançaram a condição de produto/mercadoria.

\section{Referência bibliográfica:}

ARILHA, Margareth \& MEDADA, Benedito (orgs.) - Homens e masculinidades: outras palauras. São Paulo, Editora 34, 1997.

BREEN, Dana (org.) - O enigma dos sexos: perspectivas psicanalíticas contemporâneas da feminilidade e da masculinidade. Rio de Janeiro, Imago, 1998.

CAMARGO, Francisco \& HOFF, Tânia. Erotismo e mídia. São Paulo:Expressão e Arte, 2002.

DURAND, Gilbert - O Imaginário. Rio de Janeiro, Difel, 1998.

DURAND, Gilbert - As estruturas antropológicas do imaginário. São Paulo, Martins Fontes, 1997.

FOUCAULT, Michel - Vigiar e punir: nascimento da prisão. Petrópolis, Vozes, 1987.

Janeiro, Graal, 1999.

- História da sexualidade I: a vontade de saber. Rio de

GIDDENS, Anthony - A transformação da intimidade: sexualidade, amor \& erotismo nas sociedades modernas. São Paulo, Editora UNESP, 1993.

- A estética da mercadoria. São Paulo, Editora UNESP, 1998.

KURZ, Robert - "A comercialização da alma". Folha de São Paulo, Caderno Mais, 11/02/2001, p. 4-7.

LINS, Daniel (org.). A dominação masculina revisitada. Campinas, SP: Papirus, 1998a. LOTMAN, Iuri y Escuela de Tartu - Semiótica de la Cultura. Madrid, Catedra, 1979. 
LOTMAN, Iuri et all. - Ensaios de Semiótica soviética. Lisboa, Livros Horizonte, 1981.

MARTINS, Renato Luiz - "Do erotismo à parte maldita". In: NOVAES, Adauto (org.) - $O$ desejo. São Paulo, Companhia das Letras, 1995. RIBEIRO, Renato Janine (org.) - Recordar Focault. São Paulo, Brasiliense, 1985.

Notas:

${ }^{1}$ Doutora em Letras pela Universidade de São Paulo -USP e professora da Pós-graduação da Escola Superior de Propaganda e Marketing - ESPM. É co-autora dos livros Erotismo e Mídia, pela editora Expressão e Arte em 2002, e Redação Publicitária, pela editora Campus em 2004.

${ }^{2}$ A escolha das revistas foi orientada pela preocupação de abranger os níveis sócio-econômicos A, B, C e D: Íntima, Nova, Marie Claire, Claudia, Playboy, Raça, G Magazine, Sex Simbol, Contigo, Capricho, Tv Brasil e Viva! Em 2004, observa-se o crescimento do número de campanhas e peças com imagens de corpos masculinos fora do padrão homem-provedor.

${ }^{3}$ Quadro retirado do texto/relatório final "O imaginário de Corpo masculino na Publicidade”. Trata-se de uma pesquisa realizada junto ao Programa de Pesquisa docente da Escola Superior de Propaganda e Marketing ESPM e desenvolvida no período de 2000 a 2001.

${ }^{4}$ Revista de nu masculino, dirigida ao público feminino, que teve apenas três números publicados em 2000. 